\title{
Reflexividade entre o humanismo da Escola Moderna e as TIC no ensino-aprendizagem
}

\author{
Cicera Karla Dedes-Lins \\ Universidade do Minho - Instituto de Educação
}

\begin{abstract}
Resumo
As tecnologias da informação e comunicação (TIC) têm vindo a assumir um papel hegemónico e determinante no quotidiano dos indivíduos, contribuindo, simultaneamente, para a construção de um novo paradigma na educação, que dê resposta à necessidade de uma maior formação e atualização por parte daqueles, através do desenvolvimento da sua aprendizagem. Propõe-se uma abordagem científica à relação entre os pressupostos humanistas da Escola Moderna e a mobilização das TIC, para o desenvolvimento integral do aluno. No artigo analisam-se indicadores sobre o significado de desenvolver a aprendizagem tendo em consideração os saberes, experiências e caraterísticas daqueles que aprendem, mobilizando-os para o processo a partir dos seus interesses.
\end{abstract}

Palavras-chave: reflexividade; humanismo; estratégias pedagógicas; ensino-aprendizagem; desenvolvimento integral; rede.

\begin{abstract}
Information and communication technologies (ICT) assumed progressively a hegemonic and important role in individuals daily live, building a new paradigm in education whose aim is to answer training and updating needs, through the development of the individuals learning process. Therefore, the proposal is a scientific approach to the relationship between the humanist assumptions of the Modern School and mobilizing ICT for the student's integral development. This article analyzes significance indicators of developing the learning process, taking into account the knowledge, experience and characteristics of learners, which allows the effective mobilization to learning process from its interests.
\end{abstract}

Key-words: reflexivity, humanism, pedagogic strategies, teaching-learning, integral development, network

A Escola Nova e a aprendizagem coletiva a partir da dimensão cognitiva individual

Ao invés de dar a conhecer e obrigar as crianças aos modos de vida, pensar e agir dos adultos, a escola deve, na ótica da Escola Nova valorizá-las como atores educativos e afirmar, ao mesmo tempo, um projeto educativo que esteja de acordo com um presente e um futuro que obrigam os indivíduos a aprender a viver e a enfrentar as exigências de uma sociedade democrática, tecnológica e culturalmente mais desafiante, como é o caso, por exemplo, dos desafios associados à utilização das Tecnologias da Informação e Comunicação (TIC). Segundo alguns autores, deve colocar-se no primeiro plano a educação e nunca a instrução, assim como o desenvolvimento das qualidades do carácter antes das noções do saber (Dottrens, 1974). Os defensores do Movimento da Escola Moderna recusam um projeto educacional demasiado limitado à aquisição de informação e habilidades diversas, que desvaloriza o desenvolvimento de competências cognitivas, sociais e cívicas como metas educativas essenciais. Efetivamente, como afirmou Dewey (1966), uma educação, entendida como instrução no sentido mais restrito do termo, significa que se constrói a mente a partir do exterior.

Por outro lado, de acordo, também, com os apologistas da Escola Moderna, não é possível aprender ignorando os saberes, experiências e caraterísticas daqueles que aprendem, ou seja, desconsiderando as suas aptidões e o seu grau de desenvolvimento (Claparède, 1931). No sentido do envolvimento das suas especificidades, as investigações na esfera das TIC e dos ambientes online aplicados ao ensino-aprendizagem (e-a), apontam para inúmeras vantagens à sua utilização: facilitam a aprendizagem, contribuindo para o êxito e conferindo um conteúdo mais concreto aos exercícios; estimulam o desenvolvimento das competências da comunicação e aumentam a motivação dos alunos, tendo em conta que lhe atribuem objetivos claros e auditórios verdadeiros; os alunos podem aceder a bases de conhecimentos que fornecem um grande leque de informações, assim como a dados factuais, modelos de textos e elaboração de documentos; os textos redigidos pelos alunos podem ser guardados para se analisarem, posteriormente, os erros e apreciar os progressos feitos; os alunos e o professor podem visualizar alguns aspetos do próprio processo de e-a; a pesquisa sobre a aprendizagem pode desenvolver-se, mais facilmente, e o ensino é mais documentado, devido a uma maior transparência no processo de e-a, entre outras.

Estas vantagens vêm ao encontro da perspetiva da Escola Moderna, segundo a qual o projeto de formação pessoal e social do indivíduo deve: educar para a vida em sociedades democráticas e tecnológicas culturalmente exigentes; promover a cooperação; potenciar capacidades relativamente à recolha, organização e processamento da informação, à resolução de problemas; promover a autonomia intelectual, o desenvolvimento cognitivo e uma educação integral; entre outros. As TIC e o e-learning, pelas caraterísticas que lhes são inerentes, parecem, de alguma forma, responder, positivamente, a estas e outras prioridades. Efetivamente, o recurso às TIC e aos ambientes online, nas aulas, poderá permitir aos alunos não só uma aprendizagem direta e em situação comunicativa real, como possibilitar, também, uma maior liberdade na condução do seu próprio conhecimento, tornando-se o professor um gestor e facilitador da aprendizagem (Collins, 1999; Dias, 2004; McAteer, 2002). 
Apesar do reconhecimento das virtualidades desta utilização, ainda recentemente Alves \& Rodrigues (2014) analisaram as causas da sua subutilização. Segundo Estes autores, existe uma ligação classificada como difícil entre a utilização crescente das TIC e a instituição escola, principalmente no que diz respeito aos processos de e-a. Através de um inquérito implementado em 2011, a alunos e professores do ensino secundário, procuraram apreender indicadores sobre a evolução recente da utilização das TIC, nomeadamente os computadores e a internet, assim como as respetivas implicações no modo como aquela se desenvolve nos seus diversos aspetos. A alunos e professores foi perguntado se usavam o computador e a internet na sala de aulas, qual a frequência com que o faziam e quais os fins que enquadravam a utilização.

Apesar das evidências sobre a mudança de paradigma tecnológico, a escola e os seus métodos de e-a persistem como redutos onde a mudança gerada pela transformação paradigmática não tem ainda resultados claramente percetíveis e comprováveis. Com a resolução dos problemas de infraestrutura e de acesso às TIC por parte da população escolar, não se verificou também a satisfação de necessidades solicitadas por um uso mais intenso destes instrumentos, pelo que se assume ser relevante neste tempo interpretar a forma como estes estão a ser integrados e utilizados no processo educativo, os seus fins e benefícios, assim como a sua utilização nas diferentes dimensões da vida quotidiana.

Alves \& Rodrigues (ibidem) referem que em relação às TIC é manifesta a tendência para a sua utilização no sentido do reforço do ensino centrado no professor, em contraponto ao uso reduzido em atividades pedagógicas focadas no aluno, demonstrando a presença do computador e da internet na sala de aulas só como instrumento de transmissão de conteúdos por parte do docente.

A observação de Alves \& Rodrigues (ibidem) permitiu-lhes concluir que a integração das TIC no ensino segue apenas a conceção curricular disciplinar, na qual representam mais uma disciplina ou simples acessória a mobilizar nos momentos considerados apropriados. Por outro lado, a observaram também que a integração do equipamento informático nas escolas não é desenvolvida no sentido de destacar uma conceção integradora das TIC no ensino. Sublinham a relativa subutilização dos computadores e da internet na escola, principalmente na sala de aula e sobretudo pelos alunos, o que contraria os objetivos definidos no Plano Tecnológico da Educação, em que se prevê uma maior implicação e intensidade da sua utilização. Alves \& Rodrigues (ibidem) verificaram que quase todas as disciplinas do currículo do ensino secundário registam uma baixa frequência de utilização das TIC dos alunos em sala de aulas. A maior intensidade no seu uso verifica-se no seu recurso enquanto instrumentos auxiliares da exposição das matérias, que permitam enriquecer e tornar mais atrativas as mensagem a transmitir, decrescendo a utilização em outras circunstâncias, embora o incentivo à pesquisa de conteúdos eletrónicos por parte dos alunos revele no estudo frequências médias interessantes. Destacam-se as taxas de aplicação bastante reduzidas em utilizações de maior complexidade e sofisticação, como as atividades de simulação e cálculo ou manuseamento de software educativo.

Saragoça (2005, p.285) entende que o debate sobre o papel da escola nas sociedades atuais e futuras, exigelhe novas lógicas no sentido de transformar recetores em produtores de informação e conhecimento que, no meio de fluxos de comunicação intensos e extensos, sejam capazes de aprender a sociedade da informação, onde «as tecnologias são um fim e um meio para atingir as competências e os saberes que condicionarão o percurso social a realizar pelas pessoas». No seu estudo, Saragoça confirmou a hipótese sobre a insuficiência dos conhecimentos dos professores e da dimensão e perfil das atividades desenvolvidas na área das TIC, classificado como um produto tecnológico fundamental para viver na «"sociedade em rede”» (Castells cit. por Saragoça, 2005:275), assim como aquelas com que se percebeu o papel da escola como agente de “"cibersocialização”» (Saragoça, 2005:280), para onde se estende e pode ampliar a ciberalfabetização, em que a tecnologia é reconhecida por professores e alunos como dinamizadora de ambientes educacionais facilitadores dos processos de e-a.

Morais \& Paiva (2014:962), os autores classificam como fundamental propor aos alunos abordagens multidisciplinares, com a mediação das TIC, no sentido de os preparem para enfrentar as incertezas do mundo globalizado onde a «aprendizagem e o conhecimento são os melhores instrumentos para a inserção na sociedade».

\section{O humanismo e as TIC entre o triângulo sociedade- educação-tecnologias}

As tecnologias são desde há algum tempo ligadas a algumas das mudanças mais significativas do século XX e primeiros anos do século XXI (Morais \& Paiva, 2014). No mesmo sentido, têm sido interpretadas como responsáveis por influenciar diferentes aspetos, muitas vezes significativos da realidade social, nomeadamente a estruturação de uma nova forma de organização da sociedade, perante a qual o sistema educativo deveria dar resposta através da sua adequação. Por exemplo, Morais \& Paiva (ibidem) procuraram debater as interrelações entre as esferas social, educativa e tecnológica e as possíveis influências daí resultantes para o ensino das ciências. No contexto das inter-relações referidas e da sociedade da informação, os autores sublinham a metáfora da rede e o potencial coletivo, de onde se prossegue para o destaque sobre as tecnologias e a sua relação com as escolas que procuram aprender. Através da importância atribuída a esta relação, reconhece-se a perspetiva segundo a qual entendem que a literacia não se limita às competências tecnológicas.

Os últimos autores, numa reflexão sobre $A$ sociedade da informação, a metáfora da rede e o potencial coletivo, é sublinham o significado das interdependências múltiplas, sendo elaborada uma crítica explícita às conceções reducionistas que 
consideram que a tecnologia por si só é capaz de transformar as sociedades, recusando a perspetiva do determinismo tecnológico. Nesta sociedade, sob a lógica da metáfora da rede, os alunos representam nós numa comunidade em que o conhecimento constitui um desafio coletivo, onde lhes é possível construir os seus saberes, mas também apoiar a construção dos saberes dos outros.

Morais \& Paiva (ibidem) afirmam que a prosperidade no futuro irá depender dos processos de manipulação, transmissão, armazenamento e controle da informação, logo, o papel do indivíduo dependerá da sua posição na teia, como agente disseminador da informação, onde se consiga destacar pela capacidade de mobilizar e coordenar os saberes, inteligências, imaginações e vontades. Desta perspetiva é possível entender que deve ser incentivado pedagogicamente o desenvolvimento de processos que apoiem a emergência da inteligência e imaginação coletiva, potenciando a criação, iniciativa, capacidade para enfrentar o desconhecido, com versatilidade e trabalho coletivo.

A escola num ambiente com este perfil, assenta na constituição de grupos de indivíduos que interagem mutuamente na exploração e na experimentação de experiências relevantes, num sentido construtivista, seguindo objetivos e utilizando as TIC como mediadoras de uma parte relevante da sua aprendizagem. Privilegiando as abordagens pedagógicas ativas, construtivistas e experimentais, simultaneamente com a valorização da interação social, do trabalho coletivo e das relações do sujeito com o ambiente, será possível dar respostas às necessidades da natureza ativa da cognição.

Sublinham-se as vias pedagógicas abertas com base na tecnologia, que permite a exteriorização de um projeto cujo propósito pode ser revertido ou interiorizado por aquele que aprende e difundido, por meio da partilha com os outros. Neste sentido, será possível desenvolver os pressupostos da construção do conhecimento propostos por Papert (1991, 1993 cit. por Morais \& Paiva, 2014, p.956): «aprendizagem situada», que parte do contexto em que decorre; «negociação social do conhecimento» os alunos formam e atestam as suas construções em interação com outros indivíduos e com a sociedade em geral; e a «colaboração» que representa o elemento imprescindível para a negociação e aferição do conhecimento.

É neste processo de construção do conhecimento que se revelam as mais-valias das TIC através da sua função de mediação, em que as ferramentas tecnológicas podem potenciar a mudança pedagógica nas práticas e nos agentes educativos, exógena e endogenamente à escola. Segundo Senge (1990, 1995, 1998, 1999, 2000, 2002, 2005, cit. por Morais \& Paiva, 2014, p.957) o conceito de learning organizations, operacionalizado através de cinco disciplinas, com as quais adquire progressivamente diferentes níveis de consciência de si: 1. «Mestria Pessoal ou Domínio Pessoal»; 2. «Modelos mentais»; 3. «Visão partilhada»; 4. «Aprendizagem em equipa»; e 5. «Pensamento sistémico».

Na perspetiva de Morais \& Paiva (2014, p.958) com estes tipos de abordagens é conferida à escola a possibilidade de reinvenção e participando da construção do projeto social, permitindo o enquadramento legítimo das TIC e ultrapassando a tendência prejudicial de sermos «frequentemente, incapazes de fazer com elas mais do que fazíamos sem elas». De forma a desenvolver a reinvenção e participação, Morais \& Paiva (2014) entendem que devem ser proporcionadas aos alunos as ferramentas que lhes permitam a exploração total dos nutrientes cognitivos existentes, o que revela a exigência do trabalho do professor ao organizar e estruturar as atividades por níveis crescentes de complexidade no contexto do processo de integração pedagógica das TIC. Os autores sublinham a necessidade de repensar a utilização das TIC, que, segundo Miranda (2007, cit. por Morais \& Paiva, 2014, p.959), depende das perspetivas dos professores sobre as possibilidades tecnológicas para: abordar a informação; apoiar os alunos no processo de construção de conhecimento; e integrá-las no currículo através de projetos criativos.

As TIC e o papel do professor e do aluno como nós da rede na perspetiva da Escola Moderna. Uma relação entendida como necessariamente reflexiva O Movimento da Escola Moderna defende que o professor deve abster-se de impor aos alunos um ritmo de aprendizagem uniforme e estranho que desvalorize as suas experiências e saberes, e evitar, ao mesmo tempo, substituir-se aos discentes. Neste sentido, deve deixar aos alunos a autonomia necessária para fazerem aquilo que lhes compete fazer. Dewey (1966) advoga, a este propósito, que uma lição deve traduzir uma resposta a uma questão que antes de tudo deve orientar a criança a colocar-se a si própria um problema. Assim, a organização do trabalho pedagógico em vez de se centrar, tendencialmente, na atividade do professor, deve privilegiar um ambiente de aprendizagem centrado em atividade(s) desenvolvidas pelos alunos. É aqui que as TIC e o e-learning podem assumir um papel de relevo inquestionável no processo de e-a, em que apoiando uma exploração pedagógica menos dirigida, como defendem alguns autores (Bidarra, 2004; Dias, 2004; Fialho, 2002; Gélat, 2003; Pinto, 2002), sustentam uma abordagem construtivista do ensino. Nesta, perspetiva-se que o aluno utilize os seus próprios métodos e ritmos para a construção do conhecimento, passando a operar-se «uma mudança qualitativa efetiva no papel docente: de distribuidor de conhecimento, para estimulador orientador de processos de investigação e reflexão do conjunto e de cada um dos alunos.» (Fialho, 2002, p.72). Competirá ao professor, sobretudo, estimular a atividade do aluno, assumindo-se, para isso, como um organizador e/ou mediador de ambientes de aprendizagem. Esta é uma das óticas adotadas pelo Movimento da Escola Moderna, que defende que o professor deverá esforçarse por substituir as lições formais e sistemáticas por atividades, pesquisas, exercícios e experiências, 
evitando, desta forma, assumir-se como um mero aplicador de normas prescritas de modo descontextualizado.

Com o trabalho desenvolvido on-line, a função do e-learning e do professor ultrapassam a simples transmissão de conteúdos, passando a orientar o processo de construção do conhecimento do aluno, incutindo-lhe uma atitude crítica e dinâmica relativamente à multiplicidade de informações com que se confronta, permanentemente, em contexto escolar e não só (Dias, 2001; 2004). Como sublinha Bidarra (2004, p.39), «a Web desafia o utilizador a envolver-se activamente nos processos», possibilitando a experimentação de diversos percursos, obrigando à distinção entre o que é importante e secundário, convidando à criação e síntese de conteúdos a partir de várias fontes e estimulando a estruturação de novas questões. Desta forma, será uma competência do professor fazer com que o aluno compreenda que poderá construir conhecimento e fazer ciência com as informações recebidas, bastando, para isso, a indicação de percursos a seguir.

Segundo Leffa (2001, p.103), «a sociedade precisa de novos conhecimentos para enfrentar os inúmeros desafios do dia-a-dia e o professor é o profissional que, por excelência, tem condições de suprir essa necessidade». O paradigma do e-a mais desejável e ajustável à era do conhecimento deve assim pautar-se, preferencialmente, por uma pedagogia construtivista, passando a informação a ser vital para trabalhar, refletir, discursar, debater e negociar (Marlowe \& Page, 1997). Manifesta-se assim relevante que o aluno tenha conhecimentos para selecionar e organizar a informação que recolhe (Pinho, 2008).

Baptista (2014) afirma que as Novas Tecnologias da Informação e Comunicação (NTIC) aumentam a capacidade de lidar com as informações, isto é, possibilitam a criação de ambientes que integram os sistemas semióticos conhecidos e aumentam os limites da capacidade humana para reconfigurar, processar, transmitir e partilhar uma grande quantidade de informação com cada vez menos restrições de espaços e de tempo, de forma quase instantânea e com um custo económico cada vez mais reduzido. Baptista (ibidem) considera que as tecnologias ao serem utilizadas com objetivos educativos, por exemplo, para apoiar e melhorar a aprendizagem dos alunos e promover ambientes de aprendizagem, podem ser consideradas um subdomínio da tecnologia educativa. As NTIC permitem às pessoas uma interação de forma participativa e colaborativa, uma aprendizagem mútua e o desempenho do papel de construtoras do conhecimento, permitindo a estruturação de novos conhecimentos.

De forma a desenvolver a reinvenção e participação, os autores entendem que devem ser proporcionadas aos alunos as ferramentas que lhes permitam a exploração total dos nutrientes cognitivos existentes, o que revela a exigência do trabalho do professor ao organizar e estruturar as atividades por níveis crescentes de complexidade no contexto do processo de integração pedagógica das TIC. Segundo
Miranda (2007, cit. por Morais \& Paiva, 2014, p.959), o repensar da utilização das TIC depende das perspetivas dos professores sobre as possibilidades tecnológicas para: abordar a informação; apoiar os alunos no processo de construção de conhecimento; e integrá-las no currículo através de projetos criativos. Os autores focam no final do seu texto o desafio da estima dos alunos por dinâmicas de processos em paralelo e multitarefas, pelo é fundamental estruturar uma abordagem ao conceito de literacia eletrónica a partir de três dimensões: «a) dimensão cognitiva; b) dimensão socioemocional; c) dimensão técnica» (Wan, 2012, cit. por Morais \& Paiva, 2014, p.961).

Num novo paradigma na educação, no qual se procura dar resposta à necessidade de uma maior formação e atualização por parte dos alunos, através do desenvolvimento da sua aprendizagem, observam-se exemplos como os dos Personal Learning Environments (PLEs) e do e-learning the massas (Massive Open Online Course -MOOCs), onde é fundamental a integração e inserção no conectivismo proporcionado pelas redes e na criação de comunidades com base nos novos media digitais, entre outros. $\mathrm{Na}$ verdade, a Internet parece ser uma boa ferramenta para desenvolver nos alunos inúmeras competências transversais, ao nível dos métodos de trabalho e de estudo, do tratamento de informação, da comunicação, de estratégias cognitivas, relacionamento interpessoal e de grupo, entre outros. Na perspetiva de D’Eça (1998, p.45), o recurso a ambientes on-line cria novos tipos de aprendizagem, centradas no aluno (student-centered), baseadas em projetos (project-based), assentes na investigação e em respostas a questões (inquiry-based), numa aprendizagem participativa, ativa, dinâmica, em que o aluno vai construindo o seu próprio conhecimento.

Num ambiente on-line os alunos aprendem não só através da atividade de receção e expressão verbais e não-verbais, assim como aprendem também a aprender, a ser autónomos e a assumirem-se como sujeitos da sua própria aprendizagem (Lima \& Capitão, 2003; Henri \& Kaye, 2004; Oh \& Lim, 2005). Alguns estudos concluíram que os alunos com acesso à internet obtiveram resultados substancialmente melhores, na gestão da informação, capacidade de comunicação e apresentação das ideias (Bates, 1993; Pinho, 2008). Este facto permite aferir algumas conclusões relevantes acerca da importância do papel desempenhado pelos ambientes on-line, ao nível da construção do conhecimento e da transferabilidade das aprendizagens, capacidades amplamente apreciadas e valorizadas pela pelos defensores da Escola Moderna.

\section{Considerações finais}

É possível reconhecer que as ferramentas tecnológicas possibilitam aos alunos desenvolver trocas interativas e colaborativas, aos mais variados níveis, promotoras de uma socialização mais desinibidora, logo, mais saudável e enriquecedora da relação com os outros. É possível concluir que os processos de e-a não devem apenas consubstanciar processos cognitivos mas também processos sociais. Neste sentido, a interação e 
integração social dos indivíduos constitui também um factor determinante e essencial na aquisição de conhecimentos e na construção de saberes, ou seja, na transformação cognitiva. Com o recurso às TIC, operacionaliza-se uma forma de aprender que, para além de participativa, é ativa, dinâmica, com e a partir da qual o aluno estrutura o seu próprio conhecimento, configurando-se como mais estimulante e diversificada, em diversas áreas. A mobilização das TIC para os processos de e-a, permite uma mais fácil focalização dos interesses, capacidades e necessidades pessoais, ou seja, tornar-se mais individualizada, conferindo ao professor mais tempo para prestar atenção a quem a exija. Este tipo de aprendizagem, no contexto da Reflexividade entre o humanismo da Escola Moderna e a utilização das TIC no ensinoaprendizagem, permite que se complementem ritmos diferentes de aprendizagem, em simultâneo, o que acaba por ser, como se compreende, uma vantagem, ainda mais preciosa, quando se trata, por exemplo, de alunos com Necessidades Educativas Especiais e outras especificidades de aprendizagem.

\section{Referências bibliográficas}

Alves, N. \& Rodrigues, C. (2014). As Tecnologias da Informação e Comunicação na Escola: causas de uma subutilização. In Sociologia on line. 7:121-139.

Baptista, L. (2014). Novas tecnologias da informação e comunicação no contexto educacional. In Revista RETC. 14: 53-60.

Bidarra, J. (2004). Hiperespaços e materiais para formação à distância. In Dias, A., Silva, A. \& Gomes, M. (Coord.). E-learning para e-formadores (33-51). Universidade do Minho: TecMinho/Gabinete de Formação Contínua.

Claparède, E. (1931). L'éducation fonctionnelle.

Neuchatel: Paris

Collins, B. (1999). Implementing ICT in the faculty: letting a 1000 flowers bloom or managing change?. In Mirande, M.; Riemersma, J. \& Veen, W. (Ed.). De Digitale Leeromgeving. The electronic learning environment (121-136). Croningen: WoltersNoordhoff.

D’ Eça, T. (1998). Netaprendizagem. A internet na educação. Porto: Porto Editora.

Dias, P. (2001). Collaborative learning in virtual learning communities: the ttVLC project. In Dias, P. \& Freitas, C. (Org.). Actas da II Conferência Internacional de Tecnologias de Informação $e$ Comunicação na Educação, Challenges 2001 (291300). Braga: Centro de Competência Nónio Século XXI da Universidade do Minho.

Dias, P. (2004). Processos de aprendizagem colaborativa nas comunidades online. In Dias, A. \& Gomes, M. (Coord.). E-learning para e-formadores (21-31). Universidade do Minho: TecMinho/Gabinete de Formação Contínua.

Dottrens, R. (1974). Educar e instruir. Lisboa: Editorial Estampa.
Freinet, C. (1975). As técnicas Freinet da Escola Moderna. Lisboa: Editorial Estampa.

Gélat, M. (2003). Taking others perspectives in a peer interaccional setting while preparing for a written argument. In Language and Education. 17 (5): 332353.

Leffa, V. (2001). O ensino das línguas estrangeiras nas comunidades virtuais. In IV Seminário de Línguas Estrangeiras. Anais do IV Seminário de Línguas Estrangeiras. V. 1 (95-108). Goiânia: UFG.

Marlowe, B. \& Page, M. (1997). Creating and sustaining the constructivist classroom. USA: Corwin Press, Inc.

McAteer, E., Tolmie, A., Harris, R.A., Chappel, H., Marsden, S. \& Lally, V. (2002). Characterising online learning environments. Proceedings of Networked Learning. United Kingdom: University of Sheffield.

Morais, C. \& Paiva, J. (2014). Olhares e reflexões contemporâneas sobre o triângulo sociedade-educaçãotecnologias e suas influências no ensino das ciências. In Educação e Pesquisa. 40 (4): 953-964.

Pinho, A. (2008). Organização do texto argumentativo escrito em ambiente de b-learning. Tese de Doutoramento. Departamento de Educação e Tecnologia Educativa. Universidade de Aveiro.

Pinto, C. (2002). Ensino à distância utilizando TICs. Uma perspectiva global. In Jambeiro, O. \& Ramos, F. (Org.). Internet e educação a distância (1533). Salvador: UFBA, pp. 15-33.

Saragoça, J. (2005). A relação entre as novas tecnologias da informação e da comunicação e a educação: um estudo de caso. In Nico, J. (Coord.). Aprender no Alentejo ((275-291). III Encontro Regional de Educação. Évora: Departamento de Pedagogia e Educação da Universidade de Évora. 